in vivo $34: 1965-1974(2020)$

doi:10.21873/invivo.11993

\title{
Histopathological Features and Ann Arbor Stage in Periocular Lymphoma
}

\author{
MARCO ZSCHOCHE ${ }^{1}$, ANNETTE ZIMPFER ${ }^{2}$, BJÖRN O. SCHEEF ${ }^{1}$, ANSELM M. JÜNEMANN ${ }^{1}$, \\ RUDOLF F. GUTHOFF ${ }^{1}$, CHRISTIAN JUNGHANSS ${ }^{3}$, GUIDO HILDEBRANDT ${ }^{4}$, STEFFEN EMMERT $^{5}$, \\ ANDREAS ERBERSDOBLER $^{2}$, GÜNTHER KUNDT ${ }^{6}$ and VINODH KAKKASSERY ${ }^{1,7}$ \\ ${ }^{I}$ Department of Ophthalmology, University Medical Center Rostock, Rostock, Germany; \\ ${ }^{2}$ Institute of Pathology, University Medical Center Rostock, Rostock, Germany; \\ ${ }^{3}$ Department of Oncology, University Medical Center Rostock, Rostock, Germany; \\ ${ }^{4}$ Department of Radiotherapy, University Medical Center Rostock, Rostock, Germany; \\ ${ }^{5}$ Clinic and Polyclinic for Dermatology and Venereology, \\ University Medical Center Rostock, Rostock, Germany; \\ ${ }^{6}$ Institute for Biostatistics and Informatics in Medicine and Ageing Research, \\ University of Rostock, Rostock, Germany; \\ ${ }^{7}$ Department of Ophthalmology, University-Hospital Schleswig-Holstein, \\ University of Luebeck, Luebeck, Germany
}

\begin{abstract}
Background: To evaluate biodata, symptoms/signs, lymphoma type, localization, stage level, treatment choice and outcome of ocular adnexal lymphoma (OAL). Patients and Methods: A single-center retrospective analysis of 56 patients with OAL was performed from 1998 to 2018. Results: OAL involved the orbit in $44.6 \%$, the conjunctiva in $32.1 \%$, the lacrimal apparatus in $14.3 \%$ and the eyelid in $8.93 \%$. Extranodal marginal zone B-cell lymphoma (EMZL) was found in $60.7 \%$, follicular lymphoma (FL) in $21.4 \%$, diffuse large Bcell lymphoma in $7.14 \%$, mantle cell lymphoma in $5.36 \%$ and chronic lymphatic leukaemia in $5.36 \%$ patients. No relapse was seen in $76 \%$. EMZL and FL had a significantly better overall survival compared to other lymphoma types ( $p=0.002)$. Patients with Ann Arbor stage IE had a significantly better prognosis than those with stages higher than IE $(p=0.048)$. Conclusion: Our data suggest that clinicopathological features such as Ann Arbor stage influence survival.
\end{abstract}

This article is freely accessible online.

Correspondence to: Vinodh Kakkassery, MD, Department of Ophthalmology, UKSH, University of Luebeck, Ratzeburger Allee 160, 23538 Luebeck, Germany. Tel: +49 45150043911, Fax: +49 45150043914, e-mail: vinodh.kakkassery@gmail.com; Marco Zschoche, Department of Ophthalmology, University Medical Center Rostock, Doberaner Straße 140, 18057 Rostock, Germany. E-mail: marco.zschoche@gmail.com

Key Words: Periorbital lymphoma, ocular adnexal lymphoma, orbital lymphoma, survival, histopathology, Ann Arbor stage.
About a quarter of all non-Hodgkin lymphomas (NHLs) appear as extranodal manifestations and can occur in every tissue outside of the lymph nodes, for example in the structures of the ocular adnexa (OA) $(1,2)$. Lymphomas of the eye and the ocular adnexa (OAL) comprise about $1-8 \%$ of these NHL (2-4). Histological subtype, as well as other characteristics such as laterality, is a critical predictor of prognosis and management (5). In some older studies, Ann Arbor stage was evaluated as a remarkable factor for assessing prognosis (6-8). However, all the aforementioned studies are 15 to 30 years old. Therefore, there are no up to date data reflecting the actual current treatment regime outcome related to Ann Arbor stage for periocular lymphoma.

The objective of our study was to evaluate biodata, symptoms and clinical signs, lymphoma type, localization, stage and treatment choice, as well as outcome, of rare OALs which were diagnosed at our University Medical Center from 1998 to 2018. Within this process, entity-specific clinical features and prognostic factors for a favourable outcome were elaborated.

\section{Patients and Methods}

Study design and data collection. The study represents a large retrospective single-center evaluation of OAL. For data collection, ethical approval from the Ethics Committee of the University Medical Center Rostock (register no. A2017-0202, Rostock, Germany) was obtained. The study was conducted according to the tenets of the Declaration of Helsinki.

We identified 56 eligible patients with a histologically confirmed diagnosis of OAL within a period over the past 20 years, from 
January 1 in 1998 to February 1 in 2018. Data were retrospectively collected from available patient files at the Department of Ophthalmology and the Cancer Registry of the University Medical Center Rostock. For each patient, we collected data on the following variables: Age and gender, signs and symptoms of OAL, laterality, localization, histological subtype of OAL, and basic ophthalmological parameters (visual acuity in LogMAR, intraocular pressure, field of view, eye motility). We classified the patients according to the available information following the modified Ann Arbor Staging Classification and the Eighth Edition of the American Joint Committee on Cancer Cancer (AJCC) Staging manual TNM classification for $\operatorname{OAL}(9,10)$.

Statistical analysis. All statistical calculations were performed using SPSS version 25 (IBM, Armonk, NY, USA) and Microsoft Excel version 15.39 (Microsoft Corporation, Redmond, WA, USA). Descriptive statistics were computed for continuous and categorical variables. This included the mean, median, range, and standard deviation (SD) of continuous variables, frequencies and relative frequencies of categorical factors. To test for differences in ophthalmological parameters, the study group was divided into two subgroups: Affected eyes and non-affected eyes of patients. In the case of bilateral involvement, both eyes were categorized into the group of affected eyes. Symptom-diagnosis latency was defined as the time from the appearance of the first symptoms to the definitive biopsy-proven diagnosis. Testing for differences of continuous variables between the study groups was accomplished by the twosample $t$-test for independent samples or the Mann-Whitney $U$-test, as appropriate. Similarly, for dependent samples either the unpaired $t$-test or the Wilcoxon signed-rank test was used. Test selection was based on evaluating the variables for normal distribution employing the Kolmogorov-Smirnov test. Comparisons between the study groups for categorical variables were done using the chi-square test or Fisher's exact test. For paired nominal data, McNemar tests were used. Multiple statistical tests were performed to compare personal risk factors and ophthalmic parameters. The null hypothesis was defined as the assumption of equality between two variables. All $p$ values resulted from two-sided statistical tests and values of $p<0.05$ were considered to be statistically significant. The period of time to death or last follow-up was estimated using the Kaplan-Meier method. Differences between curves were assessed by Mantel's logrank test for censored survival data of the patients with OAL. Only the overall survival (OS) was examined and visualized. OS was determined as the duration from the date of histopathological diagnosis of OAL to the last date of follow-up due to death from any cause or the date of last contact in the follow-up, the latter was included in the statistical analysis as censored events. We excluded patients with a follow-up time lower than 6 months.

\section{Results}

Patients. In total, 56 patients with OAL were assessed. The median follow-up period for the whole cohort was 27.5 months (range $=1-150$ months). The entire cohort consisted of 27 male and 29 female patients. The overall median age at the time of definitive diagnosis was 70 years (range $=20$ 93 years) (Table I).

Five different entities of OAL were identified. The most frequent entity was extranodal marginal zone B-cell lymphoma
(EMZL) $(n=34)$ followed by follicular lymphoma (FL) $(n=12)$ (all of them grade 1 or 2), diffuse large B-cell lymphoma (DLBCL) $(n=4)$, mantle cell lymphoma (MCL) $(n=3)$, and chronic lymphatic leukaemia (B-CLL/SLL) $(n=3)$. Fifty-one of these lymphomas were safely categorized as primary or secondary involvement. In total, $64.7 \%(n=33)$ were primary lymphomas and $35.3 \%(n=18)$ were secondary lymphomas (Table I).

Most frequently, OAL occurred in the tissues of the orbit; $44.6 \%$ of the patients $(n=25)$ had an orbital lymphoma followed by $32.1 \%$ of patients $(n=18)$ with the conjunctiva as main localization of lymphoma. OAL of the lacrimal apparatus and the eyelid were found less frequently at $14.3 \%$ $(n=8)$ and $8.93 \%(n=5)$, respectively (Table I.). We did not find any significant differences comparing primary and secondary disease by OAL localization (both $p>0.05$; Fisher's exact test). In $80.4 \%$ of the cases unilateral and in $19.6 \%$ bilateral involvement was present (Table I). We examined whether there was a relation between laterality (unilateral versus bilateral) and primary versus secondary disease. Although primary disease was related to bilateral disease in $15.2 \%$ and secondary disease nearly twice as much in $30.0 \%$, a significant difference was not found ( $p=0.296$; Fisher's exact test). In EMZL, secondary disease was seen in $8.8 \%$ while FL, MCL, and DLBCL altogether showed secondary disease in $78.9 \%(p<0.001$; Fisher's exact test). Laterality was associated with these disease entities ( $p=0.496$; Fisher's exact test).

Signs and symptoms. A mean latency of 7.4 months ( $\mathrm{SD}=9.18$ months, median=3 months, range=3-36 months) between first symptoms and making the definite diagnosis was calculated in 55 patients. Orbital lymphoma was diagnosed later compared to conjunctival lymphoma with a longer mean and median latency ( $p=0.023$; Mann-Whitney $U$-test) (Table II).

The most frequent OAL symptoms were exophthalmos in 24 patients $(42.9 \%)$, eyelid oedema in 20 patients $(35.7 \%)$, and the typical salmon-pink patch involving the conjunctiva in 15 patients $(26.7 \%)$. A variety of specific signs and symptoms as the salmon-pink patch involving the conjunctiva and many unspecific ones such as epiphora, dry eye syndrome, or itching eyes were present. B Symptoms, i.e. unexplained fever above $38^{\circ} \mathrm{C}$, drenching night sweats, unintentional weight loss of $10 \%$ in a period over the preceding 6 months, were seen only in two patients with OAL.

Tables III-VI show the results of the analysed ophthalmological parameters. We could find significant differences between the groups of affected and non-affected eyes in intraocular pressure (IOP), perimetry and eye motility. Visual acuity was worse in the affected eyes without the difference being significant (Tables III-VI). 
Zschoche et al: Ann Arbor Stage and Outcome in Periorbital Lymphoma

Table I. Characteristics of ocular adnexal lymphoma entities including general information, classification, treatment and relapse details.

\begin{tabular}{|c|c|c|c|c|c|c|c|c|}
\hline Characteristic & & Total & EMZL & FL & DLBCL & MCL & B-CLL & SLL \\
\hline Overall $(\mathrm{n}=56), \mathrm{n}(\%)$ & & & $34(60.7 \%)$ & $12(21.4 \%)$ & $4(7.14 \%)$ & $3(5.36 \%)$ & $2(3.57 \%)$ & $1(1.79 \%)$ \\
\hline \multirow[t]{3}{*}{ Gender $(n=56)$} & Male, n (\%) & $27(48.2 \%)$ & $16(28.6 \%)$ & $4(7.14 \%)$ & $4(7.14 \%)$ & $1(1.79 \%)$ & $2(3.57 \%)$ & $0(0 \%)$ \\
\hline & Female, n (\%) & $29(51.8 \%)$ & $18(32.1 \%)$ & $8(14.3 \%)$ & $0(0 \%)$ & $2(3.57 \%)$ & $0(0 \%)$ & $1(1.79 \%)$ \\
\hline & Male:female & $1.00: 1.07$ & $1.00: 1.13$ & $1.00: 2.00$ & $1.00: 0.00$ & $1.00: 2.00$ & $1.00: 0.00$ & $0.00: 1.00$ \\
\hline \multirow[t]{4}{*}{ Age at diagnosis, years } & Median (range) & 70 & $70(20-93)$ & $68(55-81)$ & $75(61-83)$ & $69(66-75)$ & $69(64-74)$ & 73 (N/A) \\
\hline & Male & 72 & $72(44-93)$ & $65(55-78)$ & $75(61-83)$ & $69(\mathrm{~N} / \mathrm{A})$ & $69(64-74)$ & N/A \\
\hline & Female & 67 & $67(20-90)$ & $72(60-81)$ & N/A & $71(66-75)$ & N/A & $73(\mathrm{~N} / \mathrm{A})$ \\
\hline & $<60$ Years, n (\%) & $9(16.1 \%)$ & $7(12.5 \%)$ & $2(3.57 \%)$ & $0(0 \%)$ & $0(0 \%)$ & $0(0 \%)$ & $0(0 \%)$ \\
\hline $\begin{array}{l}\text { Primary involvement } \\
(\mathrm{n}=51)\end{array}$ & Yes & $33(64.7 \%)$ & $28(54.9 \%)$ & $3(5.88 \%)$ & $1(1.96 \%)$ & $0(0 \%)$ & $0(0 \%)$ & $1(1.96 \%)$ \\
\hline \multirow{2}{*}{$\begin{array}{l}\text { Lesion Iaterality }(\mathrm{n}=56) \text {, } \\
\mathrm{n}(\%)\end{array}$} & Unilateral & $45(80.4 \%)$ & $28(50.0 \%)$ & $9(16.1 \%)$ & $4(7.14 \%)$ & $1(1.79 \%)$ & $2(3.57 \%)$ & $1(1.79 \%)$ \\
\hline & Bilateral & $11(19.6 \%)$ & $6(10.7 \%)$ & $3(5.36 \%)$ & $0(0 \%)$ & $2(3.57 \%)$ & $0(0 \%)$ & $0(0 \%)$ \\
\hline \multirow[t]{4}{*}{ Location (n=56), n (\%) } & Orbit & $25(44.6 \%)$ & $15(26.8 \%)$ & $5(8.93 \%)$ & $1(1.79 \%)$ & $2(3.57 \%)$ & $1(1.79 \%)$ & $1(1.79 \%)$ \\
\hline & Conjunctiva & $18(32.1 \%)$ & $9(16.1 \%)$ & $5(8.93 \%)$ & $3(5.36 \%)$ & $0(0 \%)$ & $1(1.79 \%)$ & $0(0 \%)$ \\
\hline & Lacrimal apparatus & $8(14.3 \%)$ & $7(12.5 \%)$ & $1(1.79 \%)$ & $0(0 \%)$ & $0(0 \%)$ & $0(0 \%)$ & $0(0 \%)$ \\
\hline & Eyelid & $5(8.93 \%)$ & $3(5.36 \%)$ & $1(1.79 \%)$ & $0(0 \%)$ & $1(1.79 \%)$ & $0(0 \%)$ & $0(0 \%)$ \\
\hline \multirow{4}{*}{$\begin{array}{l}\text { Ann Arbor stage }(\mathrm{n}=51) \\
\mathrm{n}(\%)\end{array}$} & $\mathrm{Ie}$ & $30(58.8 \%)$ & $25(49,0 \%)$ & $3(5.88 \%)$ & $1(1.96 \%)$ & $0(0 \%)$ & N/A & $1(1.96 \%)$ \\
\hline & Iie & $5(9.80 \%)$ & $4(7.84 \%)$ & $1(1.96 \%)$ & $0(0 \%)$ & $0(0 \%)$ & $\mathrm{N} / \mathrm{A}$ & $0(0 \%)$ \\
\hline & Iiie & $8(15.7 \%)$ & $0(0 \%)$ & $5(9.80 \%)$ & $2(3.92 \%)$ & $1(1.96 \%)$ & N/A & $0(0 \%)$ \\
\hline & Ive & $8(15.7 \%)$ & $2(3.92 \%)$ & $3(5.88 \%)$ & $1(1.96 \%)$ & $2(3.92 \%)$ & N/A & $0(0 \%)$ \\
\hline \multirow{4}{*}{$\begin{array}{l}\text { TNM (T-stage) }(\mathrm{n}=36) \\
\mathrm{n}(\%)\end{array}$} & $\mathrm{T} 1$ & $11(30.6 \%)$ & $8(22.2 \%)$ & $2(5.56 \%)$ & $1(2.78 \%)$ & $0(0 \%)$ & N/A & $0(0 \%)$ \\
\hline & $\mathrm{T} 2$ & $21(58.3 \%)$ & $19(52.78 \%)$ & $1(2.78 \%)$ & $0(0 \%)$ & $0(0 \%)$ & N/A & $1(2.78 \%)$ \\
\hline & $\mathrm{T} 3$ & $4(11.1 \%)$ & $4(11.1 \%)$ & $0(0 \%)$ & $0(0 \%)$ & $0(0 \%)$ & N/A & $0(0 \%)$ \\
\hline & $\mathrm{T} 4$ & $0(0 \%)$ & $0(0 \%)$ & $0(0 \%)$ & $0(0 \%)$ & $0(0 \%)$ & N/A & $0(0 \%)$ \\
\hline \multirow[t]{8}{*}{ Treatment $(\mathrm{n}=56), \mathrm{n}(\%)$} & Radiation therapy & $26(46.4 \%)$ & $20(35.7 \%)$ & $5(8.93 \%)$ & $0(0 \%)$ & $0(0 \%)$ & $1(1.79 \%)$ & $0(0 \%)$ \\
\hline & Immunochemotherapy & $8(14.3 \%)$ & $1(1.79 \%)$ & $2(3.57 \%)$ & $1(1.79 \%)$ & $3(5.36 \%)$ & $1(1.79 \%)$ & $0(0 \%)$ \\
\hline & Combined treatment & $7(12.5 \%)$ & $3(5.36 \%)$ & $2(3.57 \%)$ & $2(3.57 \%)$ & $0(0 \%)$ & $0(0 \%)$ & $0(0 \%)$ \\
\hline & Watch and wait & $5(8.93 \%)$ & $2(3.57 \%)$ & $1(1.79 \%)$ & $1(1.79 \%)$ & $0(0 \%)$ & $0(0 \%)$ & $1(1.79 \%)$ \\
\hline & Surgical excision only & $3(5.36 \%)$ & $3(5.36 \%)$ & $0(0 \%)$ & $0(0 \%)$ & $0(0 \%)$ & $0(0 \%)$ & $0(0 \%)$ \\
\hline & $\begin{array}{l}\text { Immunotherapy } \\
\text { (rituximab) }\end{array}$ & $2(3.57 \%)$ & $2(3.57 \%)$ & $0(0 \%)$ & $0(0 \%)$ & $0(0 \%)$ & $0(0 \%)$ & $0(0 \%)$ \\
\hline & Chemotherapy only & $1(1.79 \%)$ & $1(1.79 \%)$ & $0(0 \%)$ & $0(0 \%)$ & & $0(0 \%)$ & $0(0 \%)$ \\
\hline & Unknown & $4(7.14 \%)$ & $2(3.57 \%)$ & $2(3.57 \%)$ & $0(0 \%)$ & $0(0 \%)$ & $0(0 \%)$ & $0(0 \%)$ \\
\hline \multirow[t]{4}{*}{ Relapse (n=50), n (\%) } & None & $38(76.0 \%)$ & $26(52.0 \%)$ & $5(10.0 \%)$ & $3(6.00 \%)$ & $2(4.00 \%)$ & $2(4.00 \%)$ & $0(0 \%)$ \\
\hline & Distant & $6(12.0 \%)$ & $1(2.00 \%)$ & $4(8.00 \%)$ & $0(0 \%)$ & $0(0 \%)$ & $0(0 \%)$ & $1(2.00 \%)$ \\
\hline & Local & $3(6.00 \%)$ & $2(4.00 \%)$ & $0(0 \%)$ & $0(0 \%)$ & $1(2.00 \%)$ & $0(0 \%)$ & $0(0 \%)$ \\
\hline & Distant and local & $3(6.00 \%)$ & $2(4.00 \%)$ & $0(0 \%)$ & $1(2.00 \%)$ & $0(0 \%)$ & $0(0 \%)$ & $0(0 \%)$ \\
\hline
\end{tabular}

EMZL: Extranodal marginal zone B-cell lymphoma; FL: follicular lymphoma; DLBCL: diffuse large B-cell lymphoma; MCL: mantle cell lymphoma; B-CLL: chronic lymphatic B-cell leukaemia; SLL: small lymphocytic lymphoma; N/A: not applicable. The percentages of the subgroups of this table are row percentages.

Classification. Thirty out of 51 patients had stage IE disease. Four patients presented with stage IIE lymphoma and eight patients in each of stages IIIE and IVE. The two cases with B symptoms occurred in stage IIE and IVE. The patients with BCLL were not staged according to the Ann Arbor Staging classification. Data were available for 31 cases of EMZL. Most of those $(n=29)$ presented with a localized stage (stage IE or IIE). Only two patients were diagnosed with stage IVE. In the patients with lymphomas other than EMZL, only six patients had a localized disease whereas 14 patients presented with disseminated lymphoma (Table I). Furthermore, we investigated whether there is a relation between Ann Arbor stage and the histopathological lymphoma subtype. Among 43 patients with
Table II. Symptom-diagnosis latency overall and according to gender and location of the tumour.

\begin{tabular}{llcc}
\hline & & \multicolumn{2}{c}{ Latency (months) } \\
\cline { 3 - 4 } Characteristic & & Mean \pm SD & Median (range) \\
\hline \multirow{2}{*}{ Total } & & $7.40 \pm 9.18$ & $3.00(0-36)$ \\
Gender & Male & $6.36 \pm 8.59$ & $3.00(0-33)$ \\
Localization & Female & $8.41 \pm 9.78$ & $5.50(0-36)$ \\
& Orbit $(\mathrm{n}=25)$ & $9.57 \pm 11.10$ & 6.00 \\
& Conjunctiva $(\mathrm{n}=18)$ & $4.38 \pm 7.69$ & 2.00 \\
\hline
\end{tabular}

SD: Standard deviation. Mann-Whitney $U$-test of symptom-diagnosis latency: Orbital vs. conjunctival location, $p=0.023$; gender: male $v s$. female, $p=0.380$. 
Table III. Visual acuity of study participants.

\begin{tabular}{|c|c|c|c|c|c|c|c|c|c|}
\hline & \multirow[b]{4}{*}{ Eye status } & \multicolumn{8}{|c|}{ Visual acuity (LogMAR) } \\
\hline & & \multicolumn{3}{|c|}{ Overall } & \multicolumn{5}{|c|}{ Comparative } \\
\hline & & \multicolumn{3}{|c|}{ Pre therapy } & \multicolumn{3}{|c|}{ Pre therapy } & \multicolumn{2}{|c|}{1 -year post therapy } \\
\hline & & Eyes, $\mathrm{n}$ & Mean \pm SD & Equiv., m & Eyes, $\mathrm{n}$ & Mean \pm SD & Equiv., m & Mean \pm SD & Equiv., $\mathrm{m}$ \\
\hline \multirow[t]{2}{*}{ Total } & Affected & 65 & $0.17 \pm 0.24$ & $6 / 9.5$ & 34 & $0.15 \pm 0.17$ & $6 / 9.5$ & $0.15 \pm 0.20$ & $6 / 9.5$ \\
\hline & Non-affected & 45 & $0.11 \pm 0.20$ & $6 / 7.5$ & 22 & $0.10 \pm 0.12$ & $6 / 7.5$ & $0.12 \pm 0.15$ & $6 / 9.5$ \\
\hline \multicolumn{10}{|l|}{ Localization } \\
\hline \multirow[t]{2}{*}{ Orbit } & Affected & 30 & $0.15 \pm 0.21$ & $6 / 9.5$ & & & & & \\
\hline & Non-affected & 20 & $0.09 \pm 0.23$ & $6 / 7.5$ & & & & & \\
\hline \multirow[t]{2}{*}{ Conjunctiva } & Affected & 19 & $0.21 \pm 0.24$ & $6 / 9.5$ & & & & & \\
\hline & Non-affected & 15 & $0.13 \pm 0.18$ & $6 / 7.5$ & & & & & \\
\hline
\end{tabular}

LogMAR: Logarithm of the minimum angle of resolution; SD: standard deviation; Equiv.: equivalent. Mann-Whitney $U$-test, pre therapy: Affected $v s$. non-affected eyes pre therapy, $p=0.111$; orbital and conjunctival tumour localization affected and non-affected eyes, both $p>0.05$. Wilcoxon signed-rank test, pre therapy $v s$. 1-year post therapy: Affected eyes, $p=0.892$; non-affected eyes, $p=0.583$. Due to bilateral manifestations, we were only able to compare the visual acuity of 65 affected eyes with 45 non-affected eyes (one case was excluded because of lack of data).

EMZL or FL with an Ann Arbor classification, 65.1\% ( $\mathrm{n}=28)$ had Ann Arbor stage IE, while only 34.9\% ( $n=15)$ had a stage higher than IE. The other eight patients with lymphomas of other subtypes (DLBCL, MCL, B-CLL) and with an Ann Arbor classification showed an opposite association: $25 \%(n=2)$ had stage IE and $75 \%(n=6)$ had a stage higher than IE (Table I).

Thirty-three primary lymphomas were classified according to the AJCC TNM classification. Additionally, we classified three lymphomas where primary or secondary manifestation was unknown at least in the T-stage. The most frequent Tstage was $\mathrm{T} 2$ in 21 cases followed by $\mathrm{T} 1$ in 11 cases; $\mathrm{T} 3$ was found in four patients. We only saw three patients with primary lymphoma and lymph node involvement: Two patients with T2N1aM0 and one with T3N1aM0 (Table I).

Treatment and outcome. The most selected treatment choice was radiotherapy. Radiotherapy as monotherapy was performed in 26 patients $(46.4 \%)$. When adding combinatory therapies, 33 patients were irradiated overall. Altogether the median radiation dose was 36 Gy (range=24-60 Gy), it has to be emphasized that there was only one special case in which a very high radiation dose of $60 \mathrm{~Gy}$ was applied. This case was a recurring grade $2 \mathrm{FL}$ of the conjunctiva in Ann Arbor stage IIIE. Side-effects were predominantly of lowgrade and early occurring, for example low-grade acute radiodermatitis or low-grade conjunctivitis totalling 10 cases each. High-grade side-effects were scarcely seen: In two cases, we observed radiation-induced retinopathy, one patient had a radiation-associated cataract and another patient developed corneal ulceration.

The other treatment choices were diverse: $14.3 \%(n=8)$ of the patients were treated with combined immunochemotherapy.
Combined therapy (for example a combination of tumour excision, radiotherapy, immunotherapy or chemotherapy) was applied in $12.5 \%(\mathrm{n}=7)$; in $8.9 \%(\mathrm{n}=5)$ no initial therapy (watchful waiting) was conducted, also termed as watch-andwait approach. Furthermore, in 5.4\% ( $n=3)$, surgical tumour excision alone, in $3.6 \%(n=2)$ immunotherapy with rituximab alone and in $1.79 \%(n=1)$ chemotherapy alone were conducted. In $7.1 \%(n=4)$ of the cases therapy remained unknown and could not be extracted from the files (Table I).

Several different combinations of chemotherapy or immunochemotherapy were applied. The combination of rituximab with the chemotherapy scheme of cyclophosphamide, hydroxydaunorubicin, vincristine and prednisone (R-CHOP) was conducted in half of the cases in which immunochemotherapy was performed. In two cases, rituximab was combined with bendamustine. The other two patients were treated with the rituximab, fludarabine and cyclophosphamide (R-FC) and rituximab, dexamethasone, cytarabine with cisplatin (R-DHAP) therapy schemes. Concerning chemotherapy, the combinations bleomycin/vincristine/cisplatin, vincristine/cyclophosphamide, mitoxantrone/chlorambucil/prednisone, and $\mathrm{CHOP} /$ methotrexate/cytarabine/etoposide were utilized.

Treatment outcome was evaluated by analysing local and systemic tumour control. In 50 patients, a sufficient amount of data was available to assess tumour control. Over $76 \%$ $(n=38)$ of the patients included in our study remained relapse-free during the whole follow-up. In 12 patients, at least one or more local or distant relapses occurred. Patients with distant relapse comprised six of these cases. Three patients presented with local relapse and another three patients presented with both local or distant relapse (Table I). 
Table IV. Intraocular pressure (IOP) of study participants.

\begin{tabular}{|c|c|c|c|c|c|c|c|c|}
\hline \multirow[b]{4}{*}{ Eye status } & \multicolumn{8}{|c|}{ IOP, mmHg } \\
\hline & \multicolumn{3}{|c|}{ Overall } & \multicolumn{5}{|c|}{ Comparative } \\
\hline & \multicolumn{3}{|c|}{ Pre therapy } & \multicolumn{3}{|c|}{ Pre therapy } & \multicolumn{2}{|c|}{1 -year post therapy } \\
\hline & Eyes, $\mathrm{n}$ & Mean \pm SD & Median (range) & Eyes, $\mathrm{n}$ & Mean \pm SD & Median (range) & Mean \pm SD & Median (range) \\
\hline Affected & 63 & $15.56 \pm 3.76$ & $16.0(9.00-25.0)$ & 28 & $15.43 \pm 3.82$ & $15.5(9.00-24.0)$ & $14.86 \pm 4.72$ & $14.5(8.00-26.0)$ \\
\hline Non-affected & 44 & $14.05 \pm 3.38$ & $14.0(7.00-20.0)$ & 16 & $12.75 \pm 3.92$ & $13.5(7.00-20.0)$ & $13.75 \pm 3.38$ & $14.0(7.00-19.0)$ \\
\hline
\end{tabular}

SD: Standard deviation. Student's unpaired $t$-test: Affected $v s$. non-affected eyes pre therapy, $p=0.036$; paired $t$-test, pre therapy $v s$. post therapy: affected eyes, $p>0.05$; non-affected eyes, $p>0.05$.

Survival. Fifty out of 56 patients of our study were included in the statistics. These 50 patients had a median follow-up time of 33 months (range $=6-150$ months). Twenty-one patients died during follow-up. Twenty-nine patients were still alive at the last follow-up contact. The Kaplan-Meier survival curve (Figure 1A) shows the cumulative OS for all lymphoma entities during follow-up. Median survival was 57 months. The cumulative OS at 1, 2, 5 and 10 years after diagnosis and treatment was $91.8 \%, 81.6 \%, 49.5 \%$, and $40.5 \%$.

We also compared the survival probabilities in relation to the histological lymphoma entities. We compared EMZL and FL cases with the cases of the other subtypes of lymphoma. This segmentation was made to show the difference between the low-grade lymphomas (EMZL/grade 1-2 FL) and the other mostly high-grade lymphomas. The EMZL/FL group included 40 patients, while the other group had only 10 patients. The cumulative OS at 1 year post therapy was $92.5 \%$ in the EMZL/FL group in contrast to $88.9 \%$ in group with other types. Two years post therapy, OS survival decreased to $86.1 \%$ as against $63.5 \%$, respectively. At 5 and 10 years post therapy, OS of the EMZL/FL group 1 was $61.7 \%$ and $50.5 \%$, respectively. For the group with other entities, no percentages were determinable at 5 and 10 years post therapy. The median survival time for the EMZL/FL group was not determinable, whilst that for the other group was 31 months. With Mantel's log-rank-test, the difference in the survival prognosis between groups was significant $(p=0.002)$ as expected due to the aggressiveness of the other lymphoma entities (Figure 1B).

OS compared by laterality of manifestation showed no significant difference in the log-rank-test $(p=0.912)$. Furthermore, there was also no significant difference in OS ( $p=0.858)$ between the localization of orbital and conjunctival lymphomas. In comparison of primary and secondary disease, primary disease showed a better prognosis. We calculated a $p$-value of 0.093 applying the log-rank-test, indicative for a statistical trend for a better prognosis of primary OAL disease (Figure 1C). We also
Table V. Field of view pre therapy of study participants.

\begin{tabular}{|c|c|c|c|}
\hline & & Field o & \\
\hline & & Deficiency & Intact \\
\hline Localization & Orbit $(n=17)$ & 11 & 6 \\
\hline ( $\mathrm{n}=24$ patients), $\mathrm{n}$ & Conjunctiva $(n=1)$ & 0 & 1 \\
\hline & $\begin{array}{l}\text { Lacrimal } \\
\text { apparatus }(\mathrm{n}=6)\end{array}$ & 3 & 3 \\
\hline & Eyelid $(\mathrm{n}=0)$ & 0 & 0 \\
\hline Mean defect \pm SD & Affected $(n=20)$ & $-3.17(3.35)$ & - \\
\hline$(n=30$ eyes $), d b$ & Non-affected $(n=10)$ & $-0.64(0.81)$ & - \\
\hline
\end{tabular}

SD: Standard deviation. Fisher's exact test of localization: Orbital vs. non-orbital, $p>0.05$. Mann-Whitney $U$-test of mean defect: Affected $v s$. non-affected eyes, $p=0.026$.

compared the prognosis of OAL with Ann Arbor stage IE with that of stages higher than IE and the difference was significant ( $p=0.048)$ (Figure 1D).

\section{Discussion}

This study including 56 patients with OAL is, to our knowledge, the largest and most comprehensive retrospective summary of the course of OAL disease in patients from the northern part of Germany. We confirm that OAL in general is a disease of advanced age (median age $=70$ years). In our study, the median age was slightly higher than those specified in other studies, which reported median ages between 64 and 66 years $(6,11-14)$. Males and females were almost equally affected. This is in good agreement with data from Moslehi et al. $(15,16)$. Other studies reported a female preponderance for $\mathrm{OAL}(12,13)$. Frequencies for primary $(64.7 \%)$ and secondary lymphoma $(35.3 \%)$ identified in our study were within the range for secondary involvement in other studies $(14-47 \%)(6,17,18)$. We found $80.4 \%$ patients with unilateral disease and $19.6 \%$ with bilateral involvement, 
Table VI. Motility of study participants.

\begin{tabular}{|c|c|c|c|c|c|}
\hline & & \multicolumn{2}{|c|}{ Overall $(n=50), n$} & \multicolumn{2}{|c|}{$\begin{array}{c}\text { Comparative } \\
(\mathrm{n}=23), \mathrm{n}\end{array}$} \\
\hline & & \multicolumn{2}{|c|}{$\begin{array}{l}\text { Pre therapy } \\
\text { w }\end{array}$} & \multicolumn{2}{|c|}{$\begin{array}{l}\text { Pre therapy } \rightarrow \\
\text { hin the follow-up post therapy }\end{array}$} \\
\hline & & Deficiency & Intact & Deficiency & Intact \\
\hline \multicolumn{6}{|l|}{ Localization } \\
\hline \multirow[t]{2}{*}{ Orbit } & Orbit & 19 & 6 & & \\
\hline & Conjunctiva & /a 2 & 11 & & \\
\hline \multirow[t]{2}{*}{ Conjunctiva } & $\begin{array}{l}\text { Lacrimal } \\
\text { apparatus }\end{array}$ & 2 & 6 & & \\
\hline & Eyelid & 2 & 2 & & \\
\hline
\end{tabular}

Fisher's exact test pre therapy: Orbital vs. non-orbital localization, $p=0.001$. McNemar test: comparative pre therapy $v s$. post therapy, $p=0.031$.

which is in line with the results of previous reports $(19,20)$. The two predominant local lymphoma localizations were the orbit $(44.6 \%)$ and the conjunctiva $(32.1 \%)$. Eyelid or lacrimal apparatus manifestations were less common. These results go along with current data in the literature $(15,21$ 24). As previously reported, EMZL was the most common histopathologic subtype of OAL followed by FL. DLBCL and MCL were rarely diagnosed $(12,25,26)$.

Mean symptom to diagnosis latency was 7.4 months overall ( $\mathrm{SD}=9.18$ months, median=3 months), indicating that first $\mathrm{OAL}$ symptoms are often misinterpreted and signs and symptoms masquerade as conjunctivitis or dacryoadenitis, for example. Similar latencies have been reported in the literature $(8,13,24)$. We also found a significant difference between diagnosis of lymphoma for those occurring in the orbit and in the conjunctiva, showing that orbital lymphomas are detected later than conjunctival lymphomas. These findings reflect that, due to rarity of these tumours, many clinicians may not regularly encounter them in practice, leading to delayed diagnosis. In this study, we also analysed basic ophthalmological parameters pretherapeutically to show the impact of OAL on visual acuity, intraocular pressure and others. We compared this data to the post therapeutically state to quantify the progress of these parameters and to show how therapy can positively affect these. Half of the patients with available data had a lack of bulbar motility pre-therapeutically. Our study showed that these motility deficiencies were mostly reversible after therapy (Tables III-VI).

We classified patients according to the modified Ann Arbor staging classification (9) and the primary lymphoma patients also according to the AJCC TNM staging system for primary OAL (10). The distribution of the Ann Arbor stages was mostly consistent with those reported in the literature (6, 17). The clustering of cases in stage IE is caused by the preponderance of low-grade EMZL lymphomas, which are often classified as stage IE. The TNM staging showed a distribution of T-stage with only slight differences from the data reported in literature $(20,27)$.

Radiotherapy was the most commonly applied therapy for OAL. Nearly half of our cohort were treated with radiation therapy. The efficacy of radiotherapy has been corroborated by many studies which showed excellent response rates and only minor side-effects $(14,28-33)$. The median radiation dose given was 36 Gy over 18 courses, which corresponds to the current guidelines for the treatment of high-grade OAL. The current guidelines from the International Lymphoma Radiation Oncology Group for low-grade OAL recommend a cumulative radiation dose of 24-25 Gy (34). As reported in other studies, side-effects of radiation therapy were predominantly mild and more severe side-effects not common $(14,28-33)$, especially in patients with primary EMZL and Ann Arbor stage IE (33). Immunochemotherapy was the second most often conducted therapy. R-CHOP was the most common combinatory therapy regimen, which is in good agreement with the literature $(35,36)$.

To evaluate the therapy-outcome we also assessed the occurrence of lymphoma relapses. During their follow-up, $76 \%$ of patients stayed relapse-free. This is in good accordance with literature data $(37,38)$.

From the 56 patients included in our study, $41.1 \%$ eventually died. The remaining 59.9\% survived (according to the last follow-up contact). Cumulative OS compared to the survival reported in literature was different in our study. Sasai et al. reported OS rates of $90 \%$ for those with lowgrade lymphomas and $50 \%$ for high-grade lymphomas at 3 years after therapy (39). Meunier et al. reported OS rates of $74 \%$ for OAL overall and $50 \%$ for those with high-grade OAL 5 years after the first therapy (13). We analysed OS for those with EMZL/FL versus the group with the remaining histological lymphoma subtypes separately. For EMZL/FL in particular, we noted that our study results for 1-year (92.5\%) and 5-year (61.7\%) OS deviated from literature data. In the literature, some authors reported 5 -year OS of over $90 \%$ for EMZL alone $(14,40)$. Olsen et al. reported a 10-year disease-specific survival of $92 \%$ for EMZL and $71 \%$ for FL in patients with orbital lymphoma (41). High-grade lymphoma such as DLBCL or MCL also had significantly worse prognosis with $41 \%$ and $32 \%$ for 10 -year diseasespecific survival, respectively (41). We confirm that the prognosis of low-grade EMZL and FL (in part) is significantly better than that of high-grade lymphoma ( $p=0.002$; Figure 1A). These findings concur with data reported in the literature confirming that survival depends significantly on malignancy of the different pathohistological entities $(7,13,14,40,42,43)$.

In addition to the histological subtype, we also confirmed that the Ann Arbor stage plays a role in prognosis of OAL. 
A
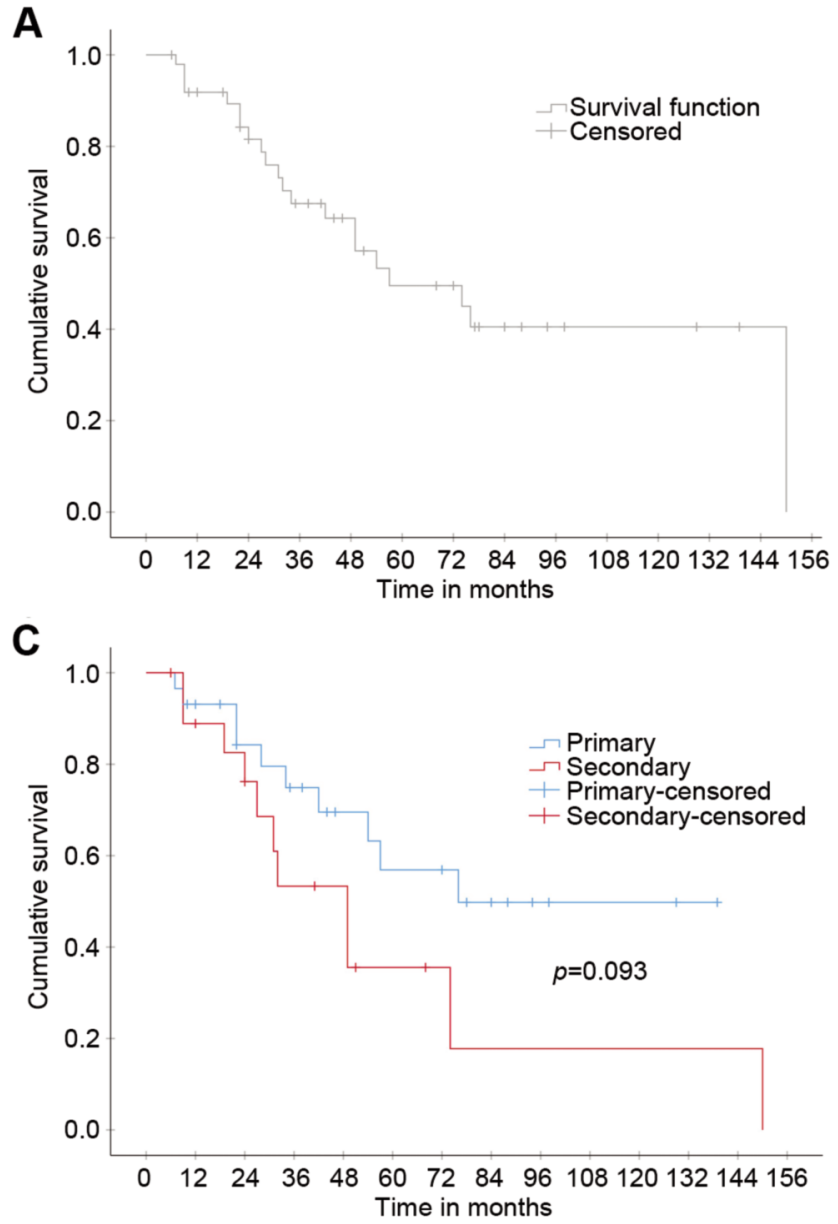

B

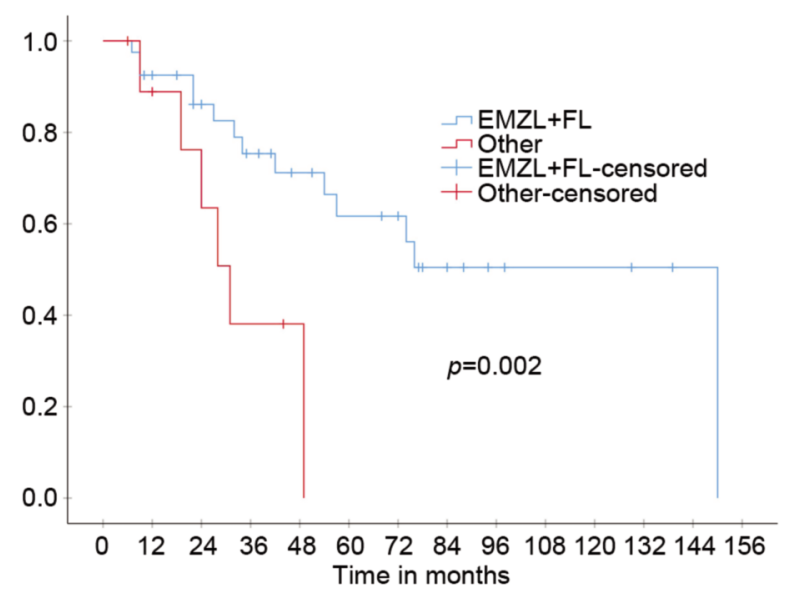

D

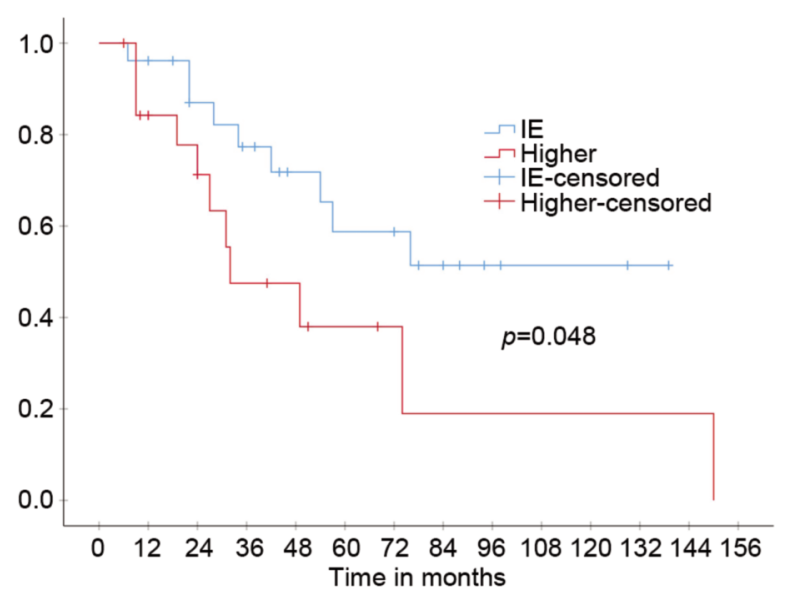

Figure 1. Kaplan-Meier overall survival (OS) curves for the whole cohort $(n=50)(A)$, in those with extranodal marginal zone B-cell lymphoma and follicular lymphoma $(E M Z L+F L)$ versus other subtypes $(B)$, with primary versus secondary disease $(C)$ and with Ann Arbor stage IE versus higher IE (D). The median OS for the whole cohort was 57 months. The cumulative OS at 1,2, 5 and 10 years after diagnosis and treatment was $91.8 \%$, $81.6 \%, 49.5 \%$, and $40.5 \%$. The pathohistological subtype was found to be a determinant in prognosis. Patients with low-grade subtypes EMZL and FL had a significantly better prognosis than those with other lymphoma types included in the study $(p=0.002)$. Those with primary ocular adnexal lymphoma $(O A L)$ tended to have better prognosis than secondary disease. The p-value of 0.093 indicated a statistical trend which needs to be proven in further studies. Ann Arbor staging classification with its graduation showed significantly better prognosis for OAL those with stage IE than those with higher stage by diagnosis ( $p=0.048)$. Therefore, Ann Arbor classification also seems to be a valid staging system for OAL.

These findings agree with studies from others which also showed the influence of Ann Arbor stage of OAL of all histopathological entities 15-30 years ago (6-8). Since then, many standards in diagnostics, histological classification and therapeutic approaches have changed and it has to be considered that patient selection is an important issue which restricts comparability between the studies. In our study, the prognosis of OAL including all types of histopathological entities with Ann Arbor stage IE was significantly better than the prognosis of those with higher stages ( $p=0.048$; Figure 1D). EMZL and FL presented more frequently in stage IE than the other subtypes. That illustrates that the Ann Arbor classification might be still a valuable staging system for OAL. Therefore, the Ann Arbor classification might be more discriminative for disease outcome than the AJCC TNM classification, rendering it an appropriate staging classification. In contrast to the 2009 AJCC TNM classification, which is only applicable for primary lymphoma (44), the modified Ann Arbor classification is easier to handle and is also applicable to secondary lymphoma.

We found no significant difference when comparing the prognosis of primary and secondary OAL, however, there was a statistical trend towards a better prognosis of primary OAL, as reported in a study by Jenkins et al. (45).

Of course, our study also has several limitations, one being the retrospective character of the study. Secondly, the study period was over 20 years due to the rarity of OAL and 
included only 56 patients. Most of the patients were assessed by different physicians; there was no consistent medical examination scheme so that acquisition of data was partly incomplete, which compromises the validity of the results to a degree. Over these 20 years, medical technologies and standards have changed. The AJCC TNM classification for OAL was only published in 2009 and has been updated several times. Moreover, the relatively short median follow-up time of 27.5 months and 33 months in the survival analysis is a factor that has to be considered when comparing Kaplan-Meier survival curves and survival probabilities in particular.

Taken together, we confirmed some fundamental characteristics of $\mathrm{OAL}$, as reported in the literature, in our large cohort. OAL appeared at an advanced age, with both genders equally affected. Clinically as well as histologically OAL presented as a heterogenous disease predominantly involving the orbit or conjunctiva as a primary and unilateral disease. The most common histological subtype was low-grade EMZL. Clinical signs and symptoms were diverse and highly associated with the localization of the lesion. Therapeutic intervention resolved lesions to a great extent and alleviated symptoms. The latency from first symptoms to the definitive diagnosis of orbital lymphomas was found to be significantly prolonged compared to conjunctival lymphomas. Radiation therapy was the most frequently applied treatment, which resulted in a good outcome and only few and mild side-effects. Fewer than a quarter of our patients experienced relapse after therapy. Most importantly, prognosis of OAL significantly depended on the histological subtype and the Ann Arbor Classification stage level.

\section{Funding}

This research did not receive any specific grant from funding agencies in the public, commercial, or not-for-profit sectors.

\section{Conflicts of Interest}

The Authors declare that they have no conflicts of interest.

\section{Authors' Contributions}

$\mathrm{MZ}$ and $\mathrm{VK}$ designed the study. MZ and VK wrote the manuscript. MZ, BOS, AMJ; RFG, GK collected and analyzed the data. AZ; CJ, $\mathrm{GH}$; SE and AE revised the manuscript. VK supervised the study. All authors have approved the final article.

\section{Acknowledgements}

S.E. is supported by the European Social Fund, reference: ESF/14BM-A55-0001/18, and the Ministry of Education, Science and Culture of Mecklenburg-West Pomerania, Germany as well as by the Damp Foundation.

\section{References}

1 Shankland KR, Armitage JO and Hancock BW: Non-Hodgkin lymphoma. Lancet 380(9844): 848-857, 2012. PMID: 22835603. DOI: $10.1016 / \mathrm{S} 0140-6736(12) 60605-9$

2 Newton R, Ferlay J, Beral V and Devesa SS: The epidemiology of non-Hodgkin's lymphoma: Comparison of nodal and extra-nodal sites. Int J Cancer 72(6): 923-930, 1997. PMID: 9378552. DOI: 10.1002/(SICI)1097-0215(19970917)72:6<923::AID$\mathrm{IJC} 1>3.0 . \mathrm{CO} ; 2-\mathrm{R}$

3 Gurney KA and Cartwright RA: Increasing incidence and descriptive epidemiology of extranodal non-Hodgkin lymphoma in parts of England and Wales. Hematol J 3(2): 95-104, 2002. PMID: 12032871. DOI: 10.1038/sj/thj/6200154

4 Freeman C, Berg JW and Cutler SJ: Occurrence and prognosis of extranodal lymphomas. Cancer 29(1): 252-260, 1972. PMID: 5007387 DOI: 10.1002/1097-0142(197201)29:1<252::aidcncr2820290138>3.0.co;2-\#

5 Tanenbaum RE, Galor A, Dubovy SR and Karp CL: Classification, diagnosis, and management of conjunctival lymphoma. Eye Vision 6: 22-22, 2019. PMID: 31372366. DOI: 10.1186/s40662-019-0146-1

6 McKelvie PA, McNab A, Francis IC, Fox R and O'Day J: Ocular adnexal lymphoproliferative disease: A series of 73 cases. Clin Exp Ophthalmol 29(6): 387-393, 2001. PMID: 11778809. DOI: 10.1046/j.1442-9071.2001.d01-18.x

7 Knowles DM, Jakobiec FA, McNally L and Burke JS: Lymphoid hyperplasia and malignant lymphoma occurring in the ocular adnexa (orbit, conjunctiva, and eyelids): A prospective multiparametric analysis of 108 cases during 1977 to 1987 . Hum Pathol 21(9): 959-973, 1990. PMID: 2394438. DOI: 10.1016/ 0046-8177(90)90181-4

8 Meunier J, Rouïc LL-L, Dendale R, Vincent-Salomon A, Asselain B, Arnaud P, Némati F, Fourquet A, Desjardins L, Plancher C, Levy C, Chaoui D, Validire P and Decaudin D: Conjunctival low-grade non-Hodgkin's lymphoma: A large single-center study of initial characteristics, natural history and prognostic factors. Leukemia Lymphoma 47(7): 1295-1305, 2006. PMID: 16923560 . DOI: 10.1080/10428190500518966

9 Carbone PP, Kaplan HS, Musshoff K, Smithers DW and Tubiana M: Report of the committee on Hodgkin's disease staging classification. Cancer Res 31(11): 1860-1861, 1971. PMID: 5121694.

10 Heegaard S, Chevez-Barrios P, White VA, Coupland SE and Finger PT: The ajcc tnm cancer staging manual, eighth edition: Ocular adnexal lymphoma. In: The AJCC TNM Cancer Staging Manual, Eighth Edition. Amin MB, Edge S, Greene F, Byrd DR, Brookland RK, Washington MK, Gershenwald JE, Compton CC, Hess KR, Sullivan DC, Jessup JM, Brierley JD, Gaspar LE, Schilsky RL, Balch CM, Winchester DP, Asare EA, Madera M, Gress DM and Meyer LR (eds.). Springer Publishing Company: USA, New York, pp. 849-854, 2017.

11 Rasmussen PK: Diffuse large b-cell lymphoma and mantle cell lymphoma of the ocular adnexal region, and lymphoma of the lacrimal gland: An investigation of clinical and histopathological features. Acta Ophthalmol 91 Thesis 5: 1-27, 2013. PMID: 24041159. DOI: 10.1111/aos.12189

12 Ferry JA, Fung CY, Zukerberg L, Lucarelli MJ, Hasserjian RP, Preffer FI and Harris NL: Lymphoma of the ocular adnexa: A study of 353 cases. Am J Surg Pathol 31(2): 170-184, 2007. PMID: 17255761. DOI: 10.1097/01.pas.0000213350.49767.46 
13 Meunier J, Lumbroso-Le Rouic L, Vincent-Salomon A, Dendale R, Asselain B, Arnaud P, Fourquet A, Desjardins L, Plancher C, Validire P, Chaoui D, Levy C and Decaudin D: Ophthalmologic and intraocular non-Hodgkin's lymphoma: A large single-centre study of initial characteristics, natural history, and prognostic factors. Hematol Oncol 22(4): 143-158, 2004. PMID: 16134191. DOI: $10.1002 /$ hon.741

14 Uno T, Isobe K, Shikama N, Nishikawa A, Oguchi M, Ueno N, Itami J, Ohnishi H, Mikata A and Ito H: Radiotherapy for extranodal, marginal zone, b-cell lymphoma of mucosaassociated lymphoid tissue originating in the ocular adnexa: A multiinstitutional, retrospective review of 50 patients. Cancer 98(4): 865-871, 2003. PMID: 12910532. DOI: $10.1002 /$ cncr.11539

15 Moslehi R, Devesa SS, Schairer C and Fraumeni JF, Jr.: Rapidly increasing incidence of ocular non-Hodgkin lymphoma. J Natl Cancer Inst 98(13): 936-939, 2006. PMID: 16818858. DOI: $10.1093 /$ jnci/djj248

16 Moslehi R, Coles FB and Schymura MJ: Descriptive epidemiology of ophthalmic and ocular adnexal non-Hodgkin's lymphoma. Expert Rev Ophthalmol 6(2): 175-180, 2011. PMID: 24353742. DOI: 10.1586/eop.11.16

17 Sullivan TJ, Whitehead K, Williamson R, Grimes D, Schlect D, Brown I and Dickie G: Lymphoproliferative disease of the ocular adnexa: A clinical and pathologic study with statistical analysis of 69 patients. Ophthalmic Plast Reconstr Surg 21(3): 177-188, 2005. PMID: 15942490. DOI: 10.1097/01.iop. 0000159173.42243.ad

18 Fung CY, Tarbell NJ, Lucarelli MJ, Goldberg SI, Linggood RM, Harris NL and Ferry JA: Ocular adnexal lymphoma: Clinical behavior of distinct World Health Organization classification subtypes. Int J Radiat Oncol Biol Phys 57(5): 1382-1391, 2003. PMID: 14630277. DOI: 10.1016/s0360-3016(03)00767-3

19 Kirkegaard MM, Rasmussen PK, Coupland SE, Esmaeli B, Finger PT, Graue GF, Grossniklaus HE, Honavar SG, Khong JJ, McKelvie PA, Mulay K, Prause JU, Ralfkiaer E, Sjo LD, Toft PB, Vemuganti GK, Thuro BA, Curtin J and Heegaard S: Conjunctival lymphoma-an international multicenter retrospective study. JAMA Ophthalmol 134(4): 406-414, 2016. PMID: 26891973. DOI: 10.1001/jamaophthalmol.2015.6122

20 Rath S, Connors JM, Dolman PJ, Rootman J, Rootman DB and White VA: Comparison of american joint committee on cancer TNM-based staging system (7th edition) and Ann Arbor classification for predicting outcome in ocular adnexal lymphoma. Orbit 33(1): 23-28, 2014. PMID: 24180616. DOI: 10.3109/ 01676830.2013 .842257

21 Verdijk RM: Lymphoproliferative tumors of the ocular adnexa. Asia Pac J Ophthalmol 6(2): 132-142, 2017. PMID: 28399341. DOI: $10.22608 / \mathrm{APO} .2016209$

22 Sjo LD: Ophthalmic lymphoma: Epidemiology and pathogenesis. Acta Ophthalmol 87 Thesis 1: 1-20,2009. PMID: 19178392. DOI: 10.1111/j.1755-3768.2008.01478.x

23 Richards H, Ramsden C, Naidoo R, Yvon C, Jacob E and Mohamedbhai S: Ocular adnexal lymphomas: A review. Expert Rev Ophthalmol 12(2): 133-148, 2017. DOI: 10.1080/17469899. 2017.1280394

24 Asproudis I, Gorezis S, Charonis GC, Tolis C, Tsanou E and Agnantis NJ: Mucosa-associated lymphoid tissue lymphoma of the lacrimal gland-a case report. In Vivo 19(6): 1105-1109, 2005. PMID: 16277031.
25 White WL, Ferry JA, Harris NL and Grove AS, Jr.: Ocular adnexal lymphoma. A clinicopathologic study with identification of lymphomas of mucosa-associated lymphoid tissue type. Ophthalmology 102(12): 1994-2006, 1995. PMID: 9098307. DOI: $10.1016 / \mathrm{s} 0161-6420(95) 30764-6$

26 Coupland SE, Krause L, Delecluse HJ, Anagnostopoulos I, Foss HD, Hummel M, Bornfeld $\mathrm{N}$, Lee WR and Stein $\mathrm{H}$ : Lymphoproliferative lesions of the ocular adnexa. Analysis of 112 cases. Ophthalmology 105(8): 1430-1441, 1998. PMID: 9709754. DOI: 10.1016/S0161-6420(98)98024-1

27 Aronow ME, Portell CA, Rybicki LA, Sweetenham JW and Singh AD: Ocular adnexal lymphoma: Assessment of a tumornode-metastasis staging system. Ophthalmology 120(9): 19151919, 2013. PMID: 23664470. DOI: 10.1016/j.ophtha. 2013.02.003

28 Woolf DK, Kuhan H, Shoffren O, Akinnawo EM, Sivagurunathan B, Boyce H and Plowman PN: Outcomes of primary lymphoma of the ocular adnexa (orbital lymphoma) treated with radiotherapy. Clin Oncol 27(3): 153-159, 2015. PMID: 25455843. DOI: 10.1016/j.clon.2014.10.002

29 Parikh RR, Moskowitz BK, Maher E, Della Rocca D, Della Rocca R, Culliney B, Shapira I, Grossbard ML, Harrison LB and $\mathrm{Hu} \mathrm{K}$ : Long-term outcomes and patterns of failure in orbital lymphoma treated with primary radiotherapy. Leukemia Lymphoma 56(5): 1266-1270, 2015. PMID: 25356924. DOI: 10.3109/10428194.2014.979415

30 Hata M, Omura M, Koike I, Tomita N, Iijima Y, Tayama Y, Odagiri K, Minagawa Y, Ogino I and Inoue T: Treatment effects and sequelae of radiation therapy for orbital mucosa-associated lymphoid tissue lymphoma. Int J Radiat Oncol Biol Phys 81(5): 1387-1393, 2011. PMID: 20950950. DOI: 10.1016/j.ijrobp. 2010.07.1992

31 Goda JS, Le LW, Lapperriere NJ, Millar BA, Payne D, Gospodarowicz MK, Wells W, Hodgson DC, Sun A, Simpson R and Tsang RW: Localized orbital mucosa-associated lymphoma tissue lymphoma managed with primary radiation therapy: Efficacy and toxicity. Int J Radiat Oncol Biol Phys 81(4): e659666, 2011. PMID: 21640514. DOI: 10.1016/j.jirobp.2011.03.050

32 Ohga S, Nakamura K, Shioyama Y, Sasaki T, Yamaguchi T, Yoshitake T, Terashima K, Asai K, Matsumoto K and Honda H: Treatment outcome of radiotherapy for localized primary ocular adnexal malt lymphoma-prognostic effect of the AJCC tumornode-metastasis clinical staging system. Anticancer Res 35(6): 3591-3597, 2015. PMID: 26026132.

33 Ohga S, Nakamura K, Shioyama Y, Sasaki T, Yoshitake T, Atsumi K, Terashima K, Asai K, Matsumoto K, Yoshikawa H, Kawano Y and Honda H: Radiotherapy for early-stage primary ocular adnexal mucosa-associated lymphoid tissue lymphoma. Anticancer Res 33(12): 5575-5578, 2013. PMID: 24324100.

34 Yahalom J, Illidge T, Specht L, Hoppe RT, Li YX, Tsang R, Wirth A and International Lymphoma Radiation Oncology G: Modern radiation therapy for extranodal lymphomas: Field and dose guidelines from the international lymphoma radiation oncology group. Int J Radiat Oncol Biol Phys 92(1): 11-31, 2015. PMID: 25863750. DOI: 10.1016/j.ijrobp.2015.01.009

35 Paik JS, Cho WK, Lee SE, Choi BO, Jung SE, Park GS, Kim SH, Yang SW and Cho SG: Ophthalmologic outcomes after chemotherapy and/or radiotherapy in non-conjunctival ocular adnexal malt lymphoma. Ann Hematol 91(9): 1393-1401, 2012. PMID: 22543827. DOI: 10.1007/s00277-012-1469-3 
36 Ma WL, Yao M, Liao SL, Tang JL, Wang YC, Kuo SH and Cheng AL: Chemotherapy alone is an alternative treatment in treating localized primary ocular adnexal lymphomas. Oncotarget 8(46): 81329-81342, 2017. PMID: 29113392. DOI: 10.18632/oncotarget. 18500

37 Song EK, Kim SY, Kim TM, Lee KW, Yun T, Na, II, Shin H, Lee SH, Kim DW, Khwarg SI and Heo DS: Efficacy of chemotherapy as a first-line treatment in ocular adnexal extranodal marginal zone B-cell lymphoma. Ann Oncol 19(2): 242-246, 2008. PMID: 17947227. DOI: 10.1093/annonc/ $\mathrm{mdm} 457$

38 Decaudin D, de Cremoux P, Vincent-Salomon A, Dendale R and Rouic LL: Ocular adnexal lymphoma: A review of clinicopathologic features and treatment options. Blood 108(5): 1451-1460, 2006. PMID: 16638927. DOI: 10.1182/blood-200602-005017

39 Sasai K, Yamabe H, Dodo Y, Kashii S, Nagata Y and Hiraoka M: Non-Hodgkin's lymphoma of the ocular adnexa. Acta Oncol 40(4): 485-490, 2001. PMID: 11504308. DOI: 10.1080/ 02841860121292

40 Rosado MF, Byrne GE, Jr., Ding F, Fields KA, Ruiz P, Dubovy SR, Walker GR, Markoe A and Lossos IS: Ocular adnexal lymphoma: A clinicopathologic study of a large cohort of patients with no evidence for an association with Chlamydia psittaci. Blood 107(2): 467-472, 2006. PMID: 16166588. DOI: 10.1182/blood-2005-06-2332

41 Olsen TG, Holm F, Mikkelsen LH, Rasmussen PK, Coupland SE, Esmaeli B, Finger PT, Graue GF, Grossniklaus HE, Honavar SG, Khong JJ, McKelvie PA, Mulay K, Sjo LD, Vemuganti GK, Thuro BA and Heegaard S: Orbital lymphoma - an international multicenter retrospective study. Am J Ophthalmol, 2018. PMID: 30419193. DOI: 10.1016/j.ajo.2018.11.002
42 Nakata M, Matsuno Y, Katsumata N, Takenaka T, Kobayashi Y, Narabayashi M, Kagami Y, Ikeda H, Kaneko A and Tobinai K: Histology according to the revised european-american lymphoma classification significantly predicts the prognosis of ocular adnexal lymphoma. Leukemia Lymphoma 32(5-6): 533543, 1999. PMID: 10048426. DOI: 10.3109/1042819 9909058411

43 Yu H, Du YX, Sun ZC, Fu XR, Tan N, Gong WF and Zhang MZ: Clinical features and treatment outcomes of primary ocular adnexal mucosa-associated lymphoid tissue lymphoma: A singlecenter retrospective analysis of 64 patients in China. Int J Ophthalmol 12(11): 1731-1736, 2019. PMID: 31741862. DOI: 10.18240/ijo.2019.11.11

44 Coupland SE, White VA, Rootman J, Damato B and Finger PT: A tnm-based clinical staging system of ocular adnexal lymphomas. Arch Pathol Lab Med 133(8): 1262-1267, 2009. PMID: 19653722. DOI: 10.1043/1543-2165-133.8.1262

45 Jenkins C, Rose GE, Bunce C, Cree I, Norton A, Plowman PN, Moseley I and Wright JE: Clinical features associated with survival of patients with lymphoma of the ocular adnexa. Eye 17(7): 809-820, 2003. PMID: 14528242. DOI: 10.1038/sj. eye. 6700379 